\title{
РАЗВИТИЕ СВЯЗНОЙ РЕЧИ У ДОШКОЛЬНИКОВ С РЕЧЕВОЙ ПАТОЛОГИЕЙ СРЕДСТВАМИ МУЛЬТИПЛИКАЦИОННОЙ ТЕРАПИИ'
}

\section{DEVELOPMENT OF CONNECTED SPEECH IN PRESCHOOLERS WITH SPEECH PATHOLOGY MEANS OF MULTIPLICATION THERAPY}

\section{S. Arkhipova \\ N. Pigalova}

Summary: The article deals with the problem of the development of coherent speech in preschool children with speech pathology, which requires the use of not only traditional, but also non-traditional means, one of which is cartoon therapy. The aim of the study is to develop organizational and methodological foundations for the development of coherent speech in preschool children with speech pathology by means of animation therapy.

Keywords: coherent speech, development, speech pathology, animation therapy, preschoolers with speech pathology.

\section{Введение}

$\Pi$ роблема развития связной речи дошкольников с речевой патологией является одной из важнейших в логопедической науке и практике. Являясь высшей и наиболее совершенной формой речевого взаимодействия ребенка с окружающим миром, связная речь обеспечивает ему возможность целостного восприятия, отражения и воспроизведения информации. У дошкольников с речевой патологией отмечается недоразвитие связной речи, оказывающее отрицательное влияние на их познавательное развитие, образование и социальную интеграцию.

Современные социально-экономические преобразования в обществе диктуют необходимость воспитания
Архипова Светлана Владимировна

К.n.н., дочент, ФГБОУ ВО «Мордовский государственный педагогический университет имени М.Е. Евсевьева»

(2. Саранск)

arhipova.swetlana2011@yandex.ru

Пигалова Наталья Александровна

ФГБОУ ВО «Мордовский государственный педагогический университет имени М.Е. Евсевьева» (г. Саранск) natusik_731@mail.ru

Аннотация: В статье рассматривается проблема развития связной речи у дошкольников с речевой патологией, требующая для своего решения применения не только традиционных, но и нетрадиционных средств, одним из которых является мультипликационная терапия. Целью исследования является разработка организационно-методических аспектов развития связной речи у дошкольников с речевой патологией средствами мультипликационной терапии.

Ключевые слова: связная речь, развитие, речевая патология, мультипликационная терапия, дошкольники с речевой патологией. творчески активной личности, обладающей способностью быстро и эффективно справляться с возникающими трудностями. В связи с этим для решения вопросов, непосредственно связанных с проблемами развития связной речи у дошкольников с речевой патологией, необходимо задействовать не только традиционные, но и нетрадиционные средства, одним из которых является мультипликационная терапия (мульттерапия).

В России социальный проект «Мульттерапия», инициатором и координатором которого выступал Фонд «Поддержки инициатив в области семьи и детства «Национальный детский фонд», был запущен еще в 2008 году. В его задачи входило создание межрегиональной сети детских анимационных студий, направленных на реабилитацию и творческую социализацию детей с ограни-

1 Исследование выполнено при финансовой поддержке вуза-партнера ФГБОУ ВО «Чувашский государственный педагогический университет им. И. Я. Яковлева» по теме: «Психомоторное развитие детей с речевой патологией средствами арттерапевтических технологий» (№ 129/2021, дата рег.: 01.04.2021). 
ченными возможностями здоровья или оказавшихся в трудной жизненной ситуации. В настоящее время, естественным приемником проекта «Мульттерапия», продолжившим развитие указанного направления работы на государственном уровне, выступает проект «Развитие межрегиональной сети детских анимационных студий для распространения модели творческого развития и социализации детей инновационными средствами коллективной анимационной деятельности» [12].

Продуктивная реализация процесса развития связной речи у дошкольников с речевой патологией средствами мультипликационной терапии невозможна без качественного организационно-методического обеспечения. Однако в специальной литературе крайне мало научно-методических рекомендаций, посвященных проблеме речевого развития, в том числе и развития связной речи средствами мультипликационной терапии, а технология данного процесса в контексте работы с детьми, имеющими речевую патологию, остается недостаточно неразработанной.

Данный факт определил цель работы, заключающейся в разработке организационно-методических аспектов развития связной речи у дошкольников с речевой патологией средствами мультипликационной терапии. Данные, полученные в результате опытно-экспериментальной деятельности, позволяют утверждать, что специально организованная работа детской студии анимации «Мультяшки» с использованием средств мультипликационной терапии может способствовать повышению уровня развития связной речи детей данной категории.

Представленные в статье теоретические материалы дополняют имеющиеся в научных исследованиях данные по заявленной проблематике, а практическая значимость заключается в возможности использования педагогами в коррекционно-педагогической работе по развитию связной речи дошкольников, имеющих речевую патологию, разработанной программы детской студии анимации «Мультяшки».

\section{Изложение основного материала}

Вопросы развития связной речи рассматриваются в различных направлениях многими педагогами (М.М. Алексеева, А.М. Бородич, Я.М. Георгиева, Б.М. Джандар, И.Н. Лебедева, Ф.К. Уракова, В.И. Яшина и др.), психологами (Л.С. Выготский, С.Л. Рубинштейн, Ф.А. Сохин, Д.Б. Эльконин и др.) и логопедами (Т.Д. Барменкова, И.С. Жгутова, Р.И. Лалаева, Т.Б. Филичева и др.).

Так, по мнению М.М. Алексеевой и В.И. Яшиной, под связной речью понимают смысловое развернутое высказывание, обеспечивающее общение и взаимопони- мание [1]. Связность, по словам С.Л. Рубинштейна, это «адекватность речевого оформления мысли говорящего или пишущего с точки зрения ее понятности для слушателя или читателя» [13].

Связная речь дошкольников с речевой патологией развивается с отставанием и характеризуется медленным накоплением пассивного и активного словаря, неадекватным усвоением значений слов, трудностями составления развернутых рассказов, управления лексемой в самостоятельной речевой деятельности (Т.Д. Барменкова, Р.И. Лалаева) [2; 10].

А.М. Бородич, И.С. Жгутова, Т.Б. Филичева и др. предлагают использовать для развития связной речи традиционные методы и приемы - наглядные, словесные, речевые образцы, словесные упражнения [3; 8; 16]. Однако для данной цели существует большое многообразие и нетрадиционных средств, одним из которых является мультипликационная терапия.

Мультипликационная терапия - это одно из направлений арт-терапии, терапии киноискусством. В мульттерапии выделяют два направления: активная - непосредственное создание мультфильмов и пассивная - просмотр готовых мультфильмов. В данной статье мы остановимся на активной мульттерапии.

Сущностью первого направления мультипликационной терапии является создание мультфильма, в котором принимает непосредственное участие сам ребенок. Он может быть сценаристом, режиссером-постановщиком, костюмером, актером или мастером дублирования. В процессе подготовки мультипликационного фильма у детей происходит активизация процесса восприятия лексического материала; развиваются лексико-грамматические средства языка; формируется связная речь и коммуникативная компетентность.

В исследованиях О.В. Сажиной, Д.И. Сиговатовой, Т.И. Поповой и др. мультипликационная терапия представлена в качестве нового направления коррекционной работы, оригинальной формы взаимодействия с детьми, имеющими проблемы в развитии. Авторы отмечают, что данное средство позволяет осуществлять коррекцию состояния ребенка эффективно, гармонично и естественно [14; 15].

M. Karch, F. Hofmann, C. Schmitt, M. Schneider, A.Schomig, B. Zrenner и др. рассматривают создание мультфильма как многоаспектный процесс, вбирающий в себя различные виды детской деятельности. В процессе создания мультфильма у дошкольников формируются такие важные личностные качества, как любознательность, активность, эмоциональная отзывчивость, доброта, самоконтроль, а также развиваются коммуникатив- 
ные умения и навыки, а главное - формируется связная речь [18].

S.V. Arkhipova, O.S. Grishina, N.G. Minaeva, T.A. Mikheikina, N.V. Ryabova считают, что благодаря мультипликационной терапии формируются зачатки речи; создаются тесные связи между действием, словом и предметом; активизируется речевая активность при создании новых героев и сюжетных линий; совершенствуется процесс удержания внимания на предметах и речевых действиях [17].

Кроме того, Е.А. Зелинская, Д.И. Сиговатова отмечают, что в процессе создания мультипликационного фильма идет развитие связной речи. В ходе подготовки и съемки мультфильма осуществляется накопление лексического строя речи детей, отрабатываются навыки грамматического оформления фраз. Игровая организация данной деятельности стимулирует их речевую активность, вызывает речевое подражание, а в последствии формирует настоящий диалог с мультипликационными персонажами, сверстниками или с педагогами. Кроме того, в процессе создания мультфильма дети, учатся общаться со сверстниками и взрослыми, принимать роль каждого участника при выполнении коллективного дела [9; 15].

В материалах представленной статьи мы обсуждаем результаты проведенного исследования по развитию связной речи у детей дошкольного возраста с речевой патологией с использованием средств мультипликационной терапии.

На первом этапе исследования осуществлялся анализ литературы, определялась сущность понятий «мультипликационная терапия», «связная речь», выделялись особенности речевого развития дошкольников с речевой патологией. На втором этапе осуществлялась диагностика связной речи дошкольников с речевой патологией, велась разработка содержания опытно-экспериментальной работы по развитию связной речи детей данной категории средствами мультипликационной терапии. На третьем - апробировалось содержание разработанной программы детской студии анимации «Мультяшки», осуществлялся анализ и интерпретация данных исследования, определялась его эффективность.

Опытно-экспериментальная деятельность осуществлялась на базе МБДОУ «Детский сад № 82 комбинированного вида» г. Саранск (Россия). В ней приняли участие дети старшего дошкольного возраста, имеющие логопедическое заключение «Общее недоразвитие речи, III уровень речевого развития».

Для диагностики были отобраны задания, предложенные В.П. Глуховым для обследования состояния связной речи дошкольников с общим недоразвитием речи [5; 6]. Методика включала шесть заданий, описание характера выполнения которых приведено ниже. При качественном анализе результатов диагностики учитывались объем правильно выполненных заданий и самостоятельность их выполнения дошкольниками.

Результаты диагностики показали, что при выполнении задания на определение способности составлять законченное высказывание на уровне фразы (по изображенному на картинке действию), справились лишь 15,38 \% дошкольников. Несмотря на то, что рассказ был составлен с помощью стимулирующих вопросов, его продолжение было достаточно информативно и оригинально. Частично справились с заданием, составив большую часть фраз с помощью педагога, 30,77 \% детей. Их рассказ был составлен с помощью побуждающих и наводящих вопросов, но его связность была нарушена. Благодаря наводящим вопросам экспериментатора 53,85 \% обучающихся смогли составить высказывания из 1-2 предложений, состоящих преимущественно из имён существительных и обиходных глаголов. Однако в их рассказах было нарушено смысловое соответствие продолжения рассказа.

При выполнении задания на выявление способности устанавливать лексико-смысловые отношения между предметами и переносить их в виде законченной фразы-высказывания лишь 7,69 \% дошкольников составили фразу по картинкам без ошибок согласования слов в предложении. Частично справились с заданием, установив связь лишь между несколькими предметами, передав их в виде законченной мысли, 57,69 \% детей. Не смогли составить предложения и найти логическую связь между предметами 34,62 \% дошкольников. В их рассказах отмечались замены прилагательных на существительные и изменение словообразовательных суффиксов.

Выполняя следующее задание только 11,54 \% дошкольников, прибегая к помощи взрослого в виде побуждения или некоторых стимулирующих вопросов, смогли полностью воспроизвести содержание небольшого по объему и простого по структуре литературного текста. Частично справились с заданием 46,15 \% детей. В их пересказах отмечались пропуски отдельных элементов действия или целых фрагментов. Не смогли правильно воспроизвести прослушанный текст даже по наводящим вопросам 42,31 \% дошкольников. В их пересказе имели место неточное употребление слов, нарушение связности выказывания.

С заданием на выявление способности составлять связный сюжетный рассказ на основе наглядного содержания последовательных фрагментов-эпизодов показало, что самостоятельно справились только 9,23\% дошкольников. Только при помощи наводящих вопросов 
педагога смогли составить связный сюжетный рассказ 61,54 \% детей. Они допускали неправильное употребление глаголов («беги» - «бежи», «ищу» - «искаю»), замены глаголов на прилагательные («сердится» - «сердитая»), в отдельных случаях в их рассказе наблюдалось перечисление отдельных элементов продемонстрированных наглядно эпизодов. Не удалось составить рассказ 19,23 \% дошкольников. Они не смогли самостоятельно установить смысловые предикативные отношения и передать их в правильных по структуре фразах.

Самостоятельно составить рассказ с опорой на личный опыт смогли 15,38 \% дошкольников. Большая часть его фрагментов представляла оригинальные связные фразовые высказывания о жизненных впечатлениях детей. Частично справились с заданием, составив отдельные фрагменты рассказа, содержащие в основном перечисления предметов и действий, 57,69 \% детей. Не удалось составить рассказ $26,92 \%$ дошкольников.

Самостоятельно составить описательный рассказ, отразив все основные признаки предметов, соблюдая логическую последовательность в их описании, смогли 7,69 \% дошкольников. С помощью наводящих вопросов составили описательный рассказ 53,85 \% детей. Однако в связи с бедностью активного словаря прилагательных в их рассказе отсутствовали некоторые существенные признаки предметов. Не справились с заданием 38,46 \% дошкольников. В их рассказе наблюдались нарушения использования предложно-падежных конструкций (пропуски, замена предлогов, искажение окончаний), отсутствовала последовательность изложения.

Результаты констатирующего эксперимента позволили условно выделить три дифференцированные группы дошкольников с речевой патологией в соответствии с уровнем развития связной речи. Данное распределение наглядно представлено на рисунке 1.

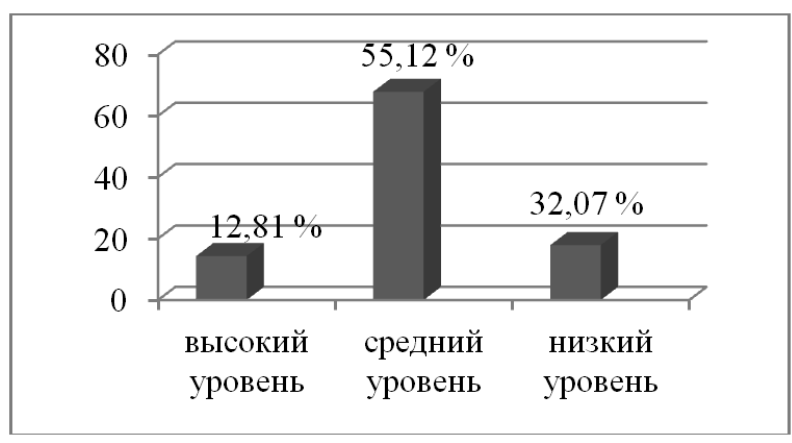

Рис. 1. Распределение дошкольников с речевой патологией по группам в соответствии с уровнем развития связной речи (по результатам констатирующего эксперимента)

Данные диагностики подтвердили наше предполо- жение о необходимости совершенствования традиционной методики развития связной речи у дошкольников с речевой патологией. Одним из путей решения данной проблемы нам видится применение коррекционно-развивающих технологий, в частности, мультипликационной терапии.

В основу опытно-экспериментальной была положена разработанная программа детской студии анимации «Мультяшки». Процесс создания мультипликационных фильмов осуществлялся дошкольниками с речевой патологией поэтапно.

На первом этапе осуществлялся выбор художественного произведения (сказки), который затем брался за основу разработки сценария будущего мультфильма. Отбирались те произведения, которые уже были хорошо знакомы детям. На данном этапе также происходило обсуждение выбранной сказки, в ходе которого дошкольники выражали свое мнение, пытаясь наиболее точно и правильно аргументировать собственные мысли.

Второй этап включал создание сценария, т.е. разработку общей концепции и идеи мультфильма, а также образов и характеров каждого из героев. В процессе разработки сценария дети подбирали новые слова и словосочетания для наиболее точной и красочной передачи сюжета, используя развернутые ответы с последующим переходом к описанию простых предметов, а затем к рассказу с несложным содержанием и ярко выраженными признаками действий. При создании сценария проводилась работа по обогащению речи дошкольников разнообразными грамматическими формами и конструкциями; развитию умения строить различные виды фраз.

На следующем этапе шла раскадровка, включающая совместный разбор действий сценария мультфильма по отдельным сценам. Делая раскладку, дети представляли, насколько будет понятен сюжет мультфильма зрителям. В ходе создания иллюстраций к мультфильму обогащался активный словарь дошкольников, развивалось вербальное и невербальное воображение.

На четвертом этапе создавались персонажи и декорации для мультфильма в различных техниках прикладного творчества. На данном этапе шло подробное обсуждение содержания каждого рисунка и пластилинового персонажа, проговаривался сюжет мультфильма, описывался внешний вид героев, что способствовало накоплению активного словаря дошкольников существительными, глаголами, прилагательными и другими частями речи.

Пятый этап включал озвучивание, выработку дикции, развитие интонации и эмоциональной выразительности 
речи. Дошкольники совершенствовали фонетические навыки, учились произносить звукоподражательные слова с различной интонацией и силой голоса, развивали речевое дыхание. При озвучивании мультфильма формировалась выразительность речи от непроизвольной эмоциональной к интонационной речевой.

На следующем этапе педагогом осуществлялся монтаж в среде специальных компьютерных программ («Adobe Premiere»). Для развития субъективной позиции детей, ощущения себя автором, мы указывали фамилии и имена детей в титрах мультфильма или их фотографии.

На заключительном этапе осуществлялся совместный просмотр и обсуждение созданного мультфильма. С целью коллективного обсуждения полученного продукта в процессе просмотра создавалась эмоционально-положительная атмосфера, которая позволяла раскрепостить детей. Совместные просмотры обладали для нас диагностической ценностью, так как позволяли оценить уровень развития монологической и диалогической речи дошкольников.

В ходе работы студии дошкольниками совместно с педагогами были созданы мультипликационные фильмы по мотивам русских-народных сказок «Колобок» и «Репка». В процессе создания мультфильмов развитие связной речи осуществлялось в определенной последовательности. Первоначально отрабатывалась обиходная лексика и побудительные фразы простейшей структуры, тем самым обеспечивалось наполнение элементарных форм общения. Постепенно вводился лексический материал, необходимый для выражения понятий абстрактного характера, и усложнялись грамматические формы фраз. Это создавало основу для перехода от диалогической речи к описательно-повествовательной, а в дальнейшем, к составлению устных и письменных связных текстов.

Развитие связной речи у дошкольников на занятиях достигалось использованием специальных приемов, нацеленных на отработку логической последовательности в пересказе событий по сюжетам мультипликационных фильмов; отображению главных связей в речи; использованию лексико-грамматических средств в оформлении связного высказывания при описании персонажей мультфильмов; активизации лексического запаса; применению различных синтаксических средств в оформлении связного высказывания; созданию текстов с использованием различных функционально-смысловых типов речи и др.

Результаты контрольного эксперимента, направленного на выявление эффективности проведенного экспериментального обучения, наглядно представлены на рисунке 2.

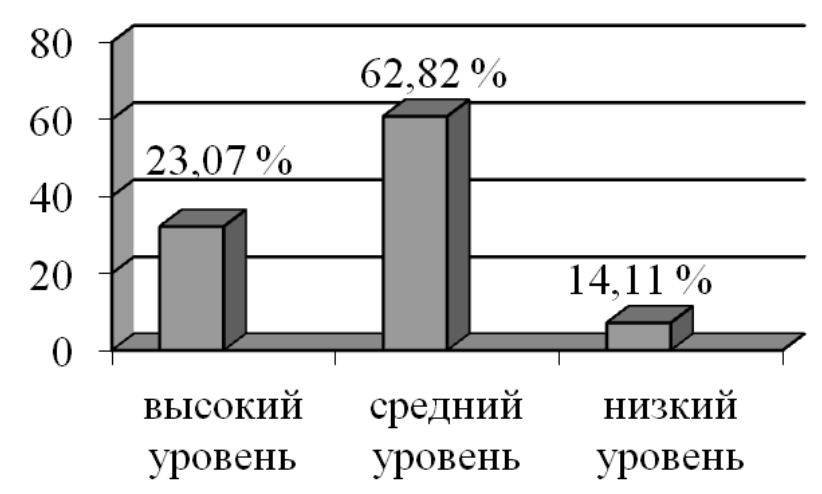

Рис. 2. Распределение дошкольников с речевой патологией по группам в соответствии с уровнем развития связной речи (по результатам контрольного эксперимента)

Исходя из результатов контрольной диагностики, были выделены три дифференцированные группы дошкольников с речевой патологией.

Первая группа - обследуемые с высоким уровнем развития связной речи. Они способны составлять законченное высказывание на уровне фразы, устанавливать лексико-смысловые отношения между предметами и при этом переносить их в виде законченной фразы-высказывания, воспроизводить небольшой по объему, и простой по структуре литературный текст, составлять связный сюжетный рассказ на основе наглядного содержания последовательных эпизодов, составлять рассказ на основе личного опыта.

Вторая группа - дети со средним уровнем развития связной речи. Их речь отличается краткостью, отсутствием логической последовательности и сжатостью изложения. Вместо активного развертывания сюжета в рассказе наблюдается перечисление отдельных элементов ситуации.

Третья группа - дошкольники с низким уровнем развития связной речи. У них наблюдаются нарушения лексико-грамматического строя речи, бедность словаря, конструкции фраз преимущественно состоят из имён существительных и обиходных глаголов. Отмечается неточность употребления слов в предложениях, нарушение использования предложно-падежных конструкций, которые выражаются в пропуске, замене предлогов, искажении окончаний.

Исходя из полученных данных констатирующего и контрольного экспериментов, можно проследить положительную динамику роста уровня развития связной речи дошкольников с речевой патологией. Данный анализ показывает, что количество детей с высоким уровнем выросло в три раза, в то время как число испытуемых с низким уровнем уменьшилось так же в три раза, а 
дошкольников со средним уровнем, по-прежнему остается большинство.

\section{Выводы}

Следует заключить, что вопросы развития связной речи средствами мультипликационной терапии в отечественной науке практически не изучались. В ходе опытно-экспериментальной работы была подтверждена предполагаемая гипотеза, что специально организованная работа в рамках деятельности детской студии анимации будет способствовать повышению уровня развития связной речи детей дошкольного возраста с речевой патологией путем формирования правильности, выразительности, четкости речи; расширения и уточнения словаря; совершенствования структуры предложения; обогащения монологической и диалогической форм речи; формирования мотивации в общении со сверстниками и взрослыми в процессе создания мультфильмов.

Материалы статьи могут быть полезны учителям-логопедам и педагогам дошкольных образовательных организаций, заинтересованным в развитии связной речи дошкольников с речевой патологией с помощью самостоятельной анимационной деятельности.

\section{ЛИТЕРАТУРА}

1. Алексеева, М.М. Методика развития речи и обучения родному языку дошкольников : учебное пособие для студ. высш. и сред. пед. учеб. заведений / М.М. Алексеева, В.И. Яшина. - 3-е изд., стереотип. - М.: Академия, 2000. - 400 с.

2. Барменкова, Т.Д. Характеристика нарушений связного речевого высказывания у детей дошкольного возраста с общим недоразвитием речи : дис. канд. пед. наук / Барменкова Татьяна Дмитриевна; МПГУ им. В.И. Ленина. - Москва, 1996. - 177 с.

3. Бородич, А.М. Методика развития речи детей: учеб. пособие для пед. ин-тов по спец. «Дошкольная педагогика и психология» / А.М. Бородич. - 2-е изд., перераб. - М.: Просвещение, 1981. -255 с.

4. Георгиева, Я.М. Развитие связной письменной речи: начальная школа / Я.М. Георгиева // Вестник Адыгейского государственного университета. - 2015. № 2. - C. 82-86. - URL: https://cyberleninka.ru/article/n/razvitie-svyaznoy-pismennoy-rechi-nachalnaya-shkola (дата обращения: 27.05.2021).

5. Глухов, В.П. Исследование особенностей связной речи старших дошкольников с ЗПР и ОНР / В.П. Глухов // Логопедия. - 2005. - № 3. - С. $23-27$.

6. Глухов, В.П. Исследование состояния связной монологической речи детей старшего дошкольного возраста с ОНР / В.П. Глухов // Дефектология. - 1986. № 6. - C. 27-32.

7. Джандар, Б.М. Текст как основа для формирования устной связной речи / Б.М. Джандар // Вестник Адыгейского государственного университета. - 2012. - № 1. - C. 198-204. - URL: https://cyberleninka.ru/article/n/tekst-kak-osnova-dlya-formirovaniya-ustnoy-svyaznoy-rechi (дата 0бращения: 27.05.2021).

8. Жгутова, И.С. Формирование связной речи у детей с ОНР / И.С. Жгутова // Ребёнок в детском саду. - 2004. - № 4. - С. 52-55.

9. Зелинская, Е.А. Эффективность методики развития коммуникативных умений детей младшего школьного возраста с интеллектуальными нарушениями средствами арттерапии / Е.А. Зелинская // Вестник Челябинского государственного университета. - 2014. - № 4 (333). - С. 118-124. -

URL: https://cyberleninka.ru/article/n/effektivnost-metodiki-razvitiya-kommunikativnyh-umeniy-detey-mladshego-shkolnogo-vozrasta-s-intellektualnyminarusheniyami (дата обращения: 27.05.2021).

10. Лалаева, Р.И. Формирование правильной разговорной речи у дошкольников / Р.И. Лалаева, Н.В. Серебрякова. - Ростов на Дону: Феникс, $2004 .-224$ с.

11. Лебедева, И.Н. Связная речь: речь в общении и речь в деятельности / И.Н. Лебедева // Специальное образование. - 2011. - № 2. - С. 88-98. URL: https://cyberleninka.ru/article/n/svyaznaya-rech-rech-v-obschenii-i-rech-v-deyatelnosti (дата обращения: 27.05.2021).

12. Международный проект «Мульттерапия». - URL: http://detskiefantazii.ru/psihologia-tvorchestva/proekt-multterapiya.html (дата 0бращения: 27.05.2021).

13. Рубинштейн, С.Л. Основы общей психологии. - СПб.: Питер, 2002. - 720 с.

14. Сажина, О.В. Мульт-терапия - новое направление в коррекционной работе с детьми с нарушением зрения / О.В. Сажина, Т.И. Попова // Актуальные проблемы современного образования: опыт и инновации: материалы Междунар. науч.-практ. конф. / под ред. В.В. Находкина. - М.: Просвещение, 2016. - C. $72-75$.

15. Сиговатова, Д.И. Психологическое сопровождение ребенка младшего школьного возраста с помощью занятий по мульттерапии / Д.И. Сиговатова // Психологическая культура и психологическое здоровье личности в современных социокультурных условиях. - 2015. - № 4. - С. 144-146. URL: https://elibrary.ru/download/elibrary_25660618_62543160.pdf (дата обращения: 27.05.2021).

16. Филичева, Т.Б. Особенности формирования речи у детей дошкольного возраста / Т.Б. Филичева. - М.: Просвещение, 1999. - 232 с.

17. Arkhipova, S.V. The formation of the coherent speech of junior schoolchildren with intellectual disabilities by means of animation-based therapy / S.V. Arkhipova, 0.S. Grishina, N.G. Minaeva, T.A. Mikheikina, N.V. Ryabova // Revista inclusions. - Vol. 6. - Numero Especial - Octubre - Diciembre, 2019. - pp. 47-62.

18. Zrenner, B. Animation in therapy: the innovative uses of haptic animation in clinical and community therapeutic practice / B. Zrenner, M. Schneider, M. Karch, F. Hofmann, A. Schomig, C. Schmitt // Chronicle of Higher Education. - 2018. - Vol. 15. - pp. 179-187.

( ) Архипова Светлана Владимировна (arhipova.swetlana2011@yandex.ru), Пигалова Наталья Александровна (natusik_731@mail.ru). 